\title{
Radiologic Changes of Anterior Cervical Discectomy and Fusion Using Allograft and Plate Augmentation: Comparison of Using Fixed and Variable Type Screw
}

\author{
Keun Oh, Chul Kyu Lee, Nam Kyu You, Sang Hyun Kim, Ki Hong Cho \\ Department of Neurosurgery, Ajou University School of Medicine, Suwon, Korea
}

\begin{abstract}
Objective: To evaluate radiologic result of anterior cervical discectomy and fusion with allobone graft and plate augmentation, and the change of radiologic outcome between screw type and insertion angle.

Methods: Retrospective review of clinical and radiological data of 29 patients. Segmental angle, height and screw angles were measured and followed. The fusion rate was assessed by plain radiography and CT scans. We divided the patients into two groups according to screw type and angles. Group A: fixed screw, Group B: variable screw. Interscrew angle was measured between most upper and lower screws with Cobb's methods.

Results: Overall fusion rate was $86.2 \%$ on plain radiography. Fusion was also assessed by CT scan and Bridwell's grading system. There was no difference in fusion and subsidence rates between two groups. Subsidence was found in 5 patients $(17.2 \%)$. Segmental lordotic angle was increased from preoperative status and maximized at the immediate postoperative period and then reduced at 1 year follow up. Segmental height showed similar increase and decrease values.

Conclusion: ACDF with allograft and plate showed favorable fusion rates, and the screw type and angle did not affect results of surgery.
\end{abstract}

Key Words: Anterior cervical fusion · Allograft, Plate construct • Fixed and Variable screws · Subsidence

\section{INTRODUCTION}

Anterior cervical discectomy and fusion (ACDF) is the most frequently performed surgical treatment for several cervical spinal diseases, including herniated disc, compressive myelopathy, trauma and degenerative disease ${ }^{5,8)}$. After decompression of spinal cord or nerve roots, interbody fusion should be performed for spinal stabilization. There are several fusion materials which have been used for several decades with effectiveness and safety ${ }^{10)}$. Most classical fusion grafts are autologous iliac bone grafts and tricortical iliac crest bone block. Autologous bone has achieved favorable fusion, but it results in an additional wound of the harvest site with risk of morbidity ${ }^{2}$. Another fusion material is polyetheretherketone (PEEK) cage and has been used with or without anterior cervical plate augmentation. Without the anterior plate, higher subsidence

- Received: August 16, 2013 • Revised: September 7, 2013

- Accepted: September 9, 2013

Corresponding Author: Nam Kyu You, MD

Department of Neurosurgery, Ajou University College of Medicine, San

5, Wonchon-dong, Yeongtong-gu, Suwon 443-721, Korea

Tel: +82-31-219-5230, 5237, Fax: + 82-31-219-5238

E-mail: nkyou@ajou.ac.kr rate has been reported ${ }^{12)}$. Besides the PEEK cage, allograft or autograft $\mathrm{ACDF}$ are usually performed with anterior plate augmentation.

Many studies regarding the PEEK cage and autograft have been reported but there have been fewer studies about allograft in cervical spine ${ }^{3,14)}$. Allografting has been used for decades and the safety and effectiveness of allografts in ACDF was reported $^{11,11,20)}$. In addition, we also studied the anterior screw insertion angle with two types of screws

\section{MATERIALS AND METHODS}

\section{Patient Selection}

Between November 2010 and June 2012, a total of 55 patients who were diagnosed with degenerative cervical disc disease underwent ACDF using allograft bone substitute and combined reinforcement with rigid plate system were selected. Exclusion criteria was less than 10 months follow up period, posterior instrumentation after ACDF, and inability to measure radiologic parameters. Patients with trauma, infection and neoplasms were excluded. Finally 29 patients (55 fusion segments) were enrolled in this study. The patients were divided 
into 2 groups according to used screws because the mean screw insertion angle was significantly different between the two screws-fixed and variable types. Group A consisted of 13 patients who underwent anterior plate fixation with fixed type screws. Insertion angle was limited at 12 degrees (Atlantis ${ }^{\mathbb{R}}$ ) and 8 degrees $\left(\right.$ Vectra $\left.^{\mathrm{B}}\right)$ in each direction from cephalad to caudal. Group B included 16 patients and they had variable screws. The mean age was $55.3 \pm 10.32$ years (range, 44 to 63 years) in Group A, and 52.6 \pm 10.32 years (range, 44 to 63 years) in Group B. There were 9 males and 5 females in group A, and 9 males and 7 females in group B. The mean follow-up period was $14.57 \pm 6.09$ months (range, 12 to 34 months). There were 3 one-level fusions and 8 two-level fusions and 4 three-level fusions. There were 2 segments of $\mathrm{C} 3-4$ fusion (zero in group B), 7 segments of C45 fusion (6 in group B), 11 segments of C5-6 fusion (15 in group B), 7 segments of C6-7 fusion (7 in group B) (Table 1).

\section{Surgical Procedure}

A single surgeon performed all operations with a standard Smith-Robinson anteromedial approach using a surgical microscope $^{5,16}$. After discectomy and decompression of the neural component, the graft bone was inserted into the disc space during gentle distraction of vertebral bodies. The allograft was commercially used freeze-dried bone from a cadaver donor. Vertebral plating system was selected according to the fusion level, from single to maximally 3 levels. A Philadelphia neck collar was applied in all patients for 1 month after surgery.

\section{Radiographic Assessment}

Regular follow up was provided immediately after surgery, at 1 month, 6 months, and 1 year after surgery, and the last follow-up. Flexion-extension lateral views were also obtained at 6 months and 1 year after surgery. Two independent neurosurgeons measured the following parameters with PACS digital software system $\left(\right.$ PiViewSTAR $^{\mathrm{TM}}$, INFINITT Co., LTD, Seoul, Korea). Segmental height, Segmental lordotic angle and Segmental interscrew angle in each time and change of segmental interspinous distance between flexion and extension in the last follow up dynamic radiography. Three dimensional Computed tomography (3D CT) was obtained at 1 year follow-up and compared with plain radiographs of bony fusion.

Segmental height was measured on the radiographs, which was the mean value of anterior and posterior height of fusion segment (Fig. 1). The subsidence was defined as $\geq$ a $2 \mathrm{~mm}$ reduction in the segmental height at 1 level fusion, $\geq$ a $4 \mathrm{~mm}$ reduction in the segmental height at 2 level fusion and $\geq a$ $6 \mathrm{~mm}$ reduction in the segmental height at 3 level fusion be-
Table 1. Demographic data

\begin{tabular}{lcl}
\hline \hline & Group A & Group B \\
\hline Cases & 13 & 16 \\
Mean age & $55.3(44-63)$ & $52.6(43-66)$ \\
Male/Female & $8 / 5$ & $9 / 7$ \\
Mean F/U (months) & $12.5(11-19)$ & $11.9(10-14)$ \\
\hline
\end{tabular}
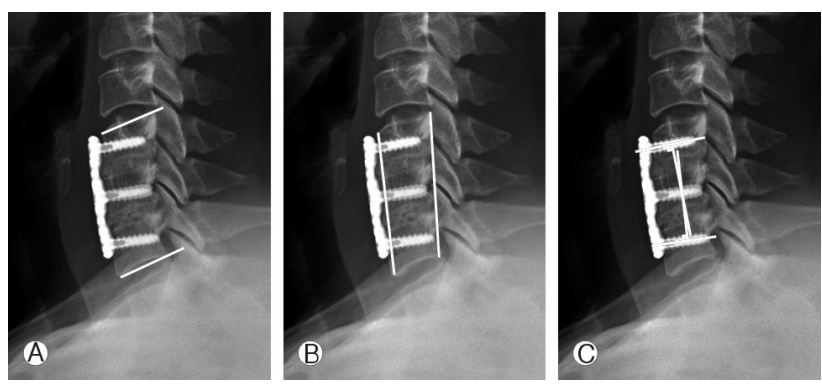

Fig. 1. Parameters in lateral view of plain radiography. (A) Measurement of segmental angle. (B) Measuring segmental height. (C) Interscrew angle measurement using Cobb's method.

Table 2. Fusion rate in plain radiography. Fisher's exact test showed $p=0.107$

\begin{tabular}{ccc}
\hline \hline Group & Fusion & None fusion \\
\hline A & $13 / 13(100 \%)$ & $0 / 13(0 \%)$ \\
B & $12 / 16(75 \%)$ & $4 / 16(25 \%)$ \\
\hline
\end{tabular}

tween immediately at the last follow-up. Segmental lordosis was measured using Cobb's method to assess the sagittal alignment. Also, the angle between the most upper and lower screws was also measured serially. The segmental screw angle was defined as the measured value by Cobb's methods between the upper and lower screws.

Nonunion was defined as the appearance of segmental instability with $\geq 2 \mathrm{~mm}$ widening of the interspinous distance on the flexion-extension lateral views at the last follow-up. CT scan was performed in 41 fused segments. We used the Bridwell's fusion grading system in CT scan ${ }^{4)}$ : Grade I: Complete fusion, Grade II: Partial fusion, Grade III: Unipolar pseudoarthrosis, Grade IV: bipolar pseudoarthrosis.

\section{RESULTS}

There was no statistically significant difference between groups A and B in demographic data (Table 1). Fusion rates were $100 \%$ in group A and $75 \%$ in group B in our previous suggested definition, the interspinous distance of fusion segment less than $2 \mathrm{~mm}$ per level (Table 2). Fisher's exact test showed no significant difference between the two groups. 
Table 3. Bridwell's fusion grade in three dimensional CT scan. Fisher's exact test showed $\mathrm{p}=0.292$

\begin{tabular}{|c|c|c|c|c|c|}
\hline \multirow[b]{2}{*}{ Group } & \multicolumn{4}{|c|}{ Bridwell's fusion Grade } & \\
\hline & 1 & II & III & IV & \\
\hline$A$ & 5 & 2 & 4 & 6 & 17 \\
\hline \multirow[t]{2}{*}{ B } & 13 & 4 & 3 & 4 & 24 \\
\hline & 18 & 6 & 7 & 10 & 41 \\
\hline
\end{tabular}

Table 4. Radiologic parameters between group and time

\begin{tabular}{llccrc}
\hline \hline Parameter & Time & Group & Mean & \multicolumn{1}{c}{ SD } & p-value \\
\hline & Pre-op & A & 2.79 & 3.67 & 0.009 \\
Segmental & Post-op & A & 7.51 & 3.79 & \\
angle & & B & 6.30 & 3.38 & 0.335 \\
& 1 year & A & 6.01 & 3.68 & 0.525 \\
& & B & 7.01 & 4.61 & \\
& Pre-op & A & 56.67 & 18.12 & 0.456 \\
Segmental & Post-op & A & 58.16 & 16.89 & 0.569 \\
Height & & B & 51.32 & 9.26 & \\
& 1 year & A & 55.87 & 17.07 & 0.661 \\
& & B & 49.29 & 9.79 & \\
& Pre-op & A & None & None & None \\
& & B & & & \\
Inter-screw & Post-op & A & 16.25 & 4.58 & 0.003 \\
angle & & B & 21.78 & 4.22 & \\
& 1 year & A & 10.60 & 7.20 & 0.105 \\
& & B & 14.46 & 4.63 & \\
\hline
\end{tabular}

There were 41 fusion segments assessed by 3 dimensional CT scan (Table 3). Complete fusion was achieved in 5 segments (29.4\%) of group A and 13 (54.1\%) of group B. Grade II fusion was seen in 2 segments (11.8\%) of group A and 4 segments (16.7\%) of group B. Grade III fusion, 4 segments (23.5 $\%)$ of group A and 3 segments (12.5\%) of group B. Grade IV fusion, 6 segments (35.3\%) of group A and 4 segments (16.7\%) of group B. Grade I fusion was more frequent in group B, but Fisher's exact test did not show statistically significance. Subsidence was found 2 cases (15.4\%) of group A and 3 cases (18.8\%) of group B and did not showed significant difference.

Other radiologic parameters were statistically analyzed (Table 4). Significant difference between the two groups was seen in the pre-operative segmental angle and immediate postoperative interscrew angle. Between the preoperative and each follow-up period, many parameters showed significant differences (Table 5). In group A the segmental angle was increased after fusion surgery and slightly decreased at the 1 year follow up period, but was not significant in later statistical analysis. Segmental height was not changed after surgery, but decreased at 1 year follow up. Mean value of interscrew angle was decreased from $16.25 \pm 4.58$ to $10.60 \pm 7.20$.

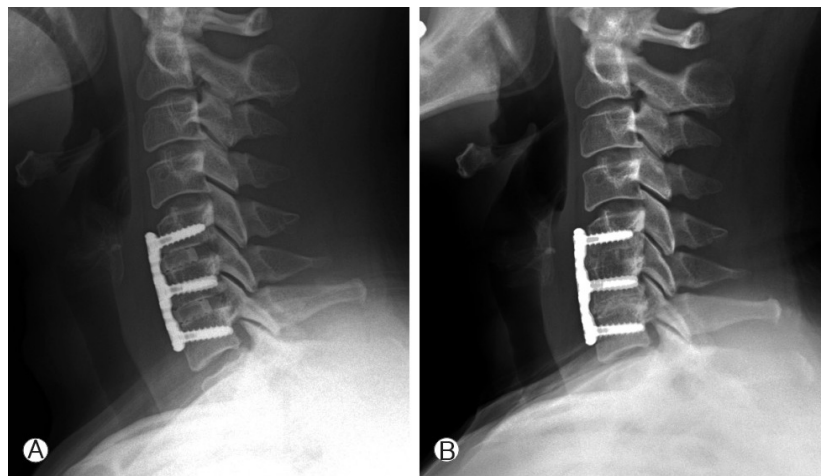

Fig. 2. Serial radiography. Interscrew angle was decreased in last follow up radiograph. (A) Immediate postoperative radiography. (B) 1 year after surgery, decreased interscrew angle comparing to Fig. 2-A.
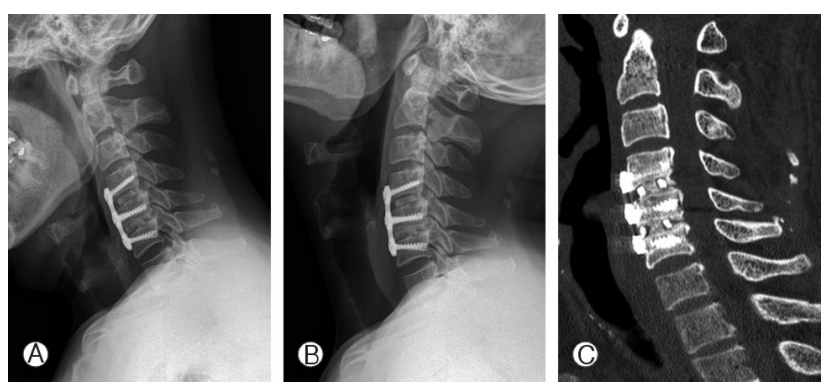

Fig. 3. Discrepancy between $x$-ray and $C$. (A) and (B). Non-union halo was seen between endplate and allobone block. (C) Bonybridge was identified in central canal of bone block.

In group B, there was no difference in segmental angles, but the segmental height was increased after surgery then decreased at 1 year follow up (Fig. 2). Mean value of interscrew angle was decreased more in group B, but there was no significant difference between two groups. There was discrepancy in fusion assessment between plain radiography and CT scan (Fig. 3). Dense radiolucent line was identified around the allograft block, however intra graft bony bridge formation was seen. Also, the interspinous distance change did not exceed $2 \mathrm{~mm}$ during flexion and extension.

\section{Complications}

Surgery-related complications were not observed. No graft malposition, migration, or mechanical failure of instruments was observed, and there was no revision surgery.

\section{DISCUSSION}

ACDF is the most favorable and familiar method for treatment of cervical degenerative diseases, and also for trauma. 
Table 5. Mean values of radiologic parameters serial to time. Wilcoxon signed rank test

\begin{tabular}{clccccc}
\hline \multirow{2}{*}{ Group } & \multirow{2}{*}{ Parameters } & \multicolumn{3}{c}{ Time } & \multicolumn{2}{c}{ p-value } \\
\cline { 3 - 6 } & & Pre-op & Post-op & 1 year & $\mathrm{a}$ & $\mathrm{b}$ \\
\hline \multirow{2}{*}{$\mathrm{A}$} & Segmental angle & $2.79 \pm 3.67$ & $7.43 \pm 3.38$ & $6.01 \pm 3.68$ & 0.001 & 0.173 \\
& Segmental Height & $56.67 \pm 18.12$ & $58.16 \pm 16.89$ & $55.87 \pm 17.07$ & 0.075 & 0.004 \\
& Inter screw angle & & $16.25 \pm 4.58$ & $10.60 \pm 7.20$ & & 0.002 \\
\multirow{2}{*}{ B } & Segmental angle & $6.51 \pm 3.79$ & $6.30 \pm 5.36$ & $7.01 \pm 4.61$ & 0.959 & 0.278 \\
& Segmental Height & $49.30 \pm 9.50$ & $51.32 \pm 9.26$ & $49.29 \pm 9.79$ & 0.004 & 0.001 \\
& & & $21.78 \pm 4.22$ & $14.46 \pm 4.63$ & & 0.001 \\
\hline
\end{tabular}

a: Comparison of preoperative and postoperative mean values.

b: Comparison of postoperative and 1 year follow up mean values.

Myelopathy or radiculopathy is treated with decompression of neural elemetns, and osseous fusion is established to stabilize the cervical spine. There have been many studies about several fusion materials and plate augmentation, but they are still controversial. Achievement of fusion without associated instrument complication may be the most favorable result in radiologic assessment, and this may also be correlated with clinical outcome. Non-union or mechanical failure of instrument causes pain or neurologic symptoms, and rarely dysfunction and injury of the esophagus or prevertebral tissues. Sometimes these complications may be treated by revision surgery which also has its own surgical risks. To assess the result of allograft fusion, we studied the radiologic analysis and also insertion orientation of anterior screws which are mandatory to bone graft fusion.

Allograft insertion causes distraction of the vertebral body because using small and loose grafts for fusion has a high risk of graft migration or malposition. Segmental height increased after surgery and also lordotic angulation increased because of lordotic curvature of the allograft and anterior fixation of plate and screw. However, in the more angled screw group, postoperative segmental lordotic angle was slightly decreased and it was caused by pulling of the vertebral body by the screw insertion.

The angle of inserted screw is associated with pull out strength. Experimental studies reported 90 degree angle has the maximum pull-out strength ${ }^{6,9)}$. Loosening of screws and retropulsing movement is not a common complication of cervical ACDF with plate augmentation, but it may be associated with soft tissue injury and non-union. In our study, the angled screw group showed slightly decreased segmental angles after operation. This may be explained by compression of vertebral bodies toward the screw and plate. According to our results, the screw angle or type does not have large role in fusion or subsidence. To maximize pull out strength, screws may be inserted with 90 degree angle to the plate and the longest size selected. Experimental ex-vivo animal or cadaver models and finite element analysis may be needed for evidence which support our results.

The fusion rate was measured by two different image modalities. Plain radiography is a simple exam which is cheap and with less radiation exposure than CT scans. Dynamic view of the cervical spine provides segmental stability and additional information about adjacent segment degeneration. The most exact assessment is the 3-dimensional CT scan, but this is not always checked during follow up. In our study, a halo like area was seen on lateral plain radiographs, but there was a bony bridge through the graft cavity, and our $86.2 \%$ fusion rate is not significantly different from other reports ${ }^{13}$.

Subsidence of overall cases was 5 of 29 patients (17.2\%). Many studies reported cage subsidence after fusion surgery and the subsidence rate varied between $43.1-50.5 \%$ by $\mathrm{Oh}$ et al, and $23.4 \%$ in the study of Yamagata et al. ${ }^{12,19)}$. The risk factors associated with subsidence have been already reported. Obesity, bone mineral density, and smoking are nonsurgical risk factors, while anteroposterior diameter of cage, and intraoperative distraction are surgical risk factors ${ }^{21}$. However subsidence does not always result in poor prognosis or aggravation of symptoms, and mostly does not cause symptoms or morbidity ${ }^{15,18,20)}$. Fusion may be achieved with subsidence of cage and nonunion may occur without subsidence ${ }^{14)}$. Fusion rates and subsidence of allograft bone is affected many other factors. Longer level fusion may be a risk factor for nonunion. Medical conditions such as osteoporosis and obesity also affect nonunion or subsidence. Repeated neck motion after surgery also affects cage subsidence. During the initial one or two months after surgery, immobilization of the neck may be necessary. Recently, recombinant human bone morphogenic protein-2 (rhBMP-2) has been used in ACDF. It still remains controversial with regard to safety in spine surgery, but additional use of rhBMP-2 may promote bone fusion after surgery ${ }^{7,17}$.

Another weak point of the allograft is the absence of an anchoring structure, such as metallic spikes in the PEEK cage. Increasing compressive force between fusion segments may 
be helpful for fusion and prevent migration of the allograft, but it also increases the risk of allograft breaks.

The relatively short follow up period in this study restricts evaluation of adjacent segment degeneration development. The retrospective nature of this review is another limitation of this study. To evaluate further information about allografts, further study may be needed with prospective, larger series and longer follow up period. Genetic study or medical status which affects bone fusion may be added in further study.

\section{CONCLUSION}

ACDF with allograft bone block and plate augmentation achieves favorable radiologic results, which is not inferior to other fusion materials. Also, the type or angle of screw fixation does not affect the fusion rate but may be associated with subsidence or decrease of segmental height.

\section{REFERENCES}

1. An HS, Simpson JM, Glover JM, Stephany J: Comparison between allograft plus demineralized bone matrix versus autograft in anterior cervical fusion. A prospective multicenter study. Spine (Phila Pa 1976) 20(20):2211-2216, 1995

2. Arrington ED, Smith WJ, Chambers HG, Bucknell AL, Davino NA: Complications of iliac crest bone graft harvesting. Clin Orthop Relat Res(329):300-309, 1996

3. Barsa P, Suchomel P: Factors affecting sagittal malalignment due to cage subsidence in standalone cage assisted anterior cervical fusion. Eur Spine J 16(9):1395-1400, 2007

4. Bridwell KH, Lenke LG, McEnery KW, Baldus C, Blanke K: Anterior fresh frozen structural allografts in the thoracic and lumbar spine. Do they work if combined with posterior fusion and instrumentation in adult patients with kyphosis or anterior column defects? Spine (Phila Pa 1976) 20(12):1410-1418, 1995

5. Cloward RB: The anterior approach for removal of ruptured cervical disks. J Neurosurg 15(6):602-617, 1958

6. DiPaola CP, Jacobson JA, Awad H, Conrad BP, Rechtine GR, $2^{\text {nd }}$ : Screw pull-out force is dependent on screw orientation in an anterior cervical plate construct. J Spinal Disord Tech 20(5): 369-373, 2007

7. Glassman SD, Howard J, Dimar J, Sweet A, Wilson G, Carreon $\mathrm{L}$ : Complications with recombinant human bone morphogenic protein-2 in posterolateral spine fusion: A consecutive series of 1,037 cases. Spine (Phila Pa 1976) 36(22):1849-1854, 2011

8. Gore DR, Sepic SB: Anterior cervical fusion for degenerated or protruded discs. A review of one hundred forty-six patients. Spine (Phila Pa 1976) 9(7):667-671, 1984

9. Hussain M, Natarajan RN, Fayyazi AH, Braaksma BR, Ander- sson GB, An HS: Screw angulation affects bone-screw stresses and bone graft load sharing in anterior cervical corpectomy fusion with a rigid screw-plate construct: A finite element model study. Spine J 9(12):1016-1023, 2009

10. Lee $\mathrm{CH}$, Hyun SJ, Kim MJ, Yeom JS, Kim WH, Kim KJ, et al: Comparative analysis of 3 different construct systems for single-level anterior cervical discectomy and fusion: Stand-alone cage, iliac graft plus plate augmentation, and cage plus plating. J Spinal Disord Tech 26(2):112-118, 2013

11. Miller LE, Block JE: Safety and effectiveness of bone allografts in anterior cervical discectomy and fusion surgery. Spine (Phila Pa 1976) 36(24):2045-2050, 2011

12. Oh HS, Shim CS, Kim JS, Lee SH: Clinical and radiological comparison of femur and fibular allografts for the treatment of cervical degenerative disc diseases. J Korean Neurosurg Soc 53(1):6-12, 2013

13. Oh JK, Kim TY, Lee HS, You NK, Choi GH, Yi S, et al: Standalone cervical cages versus anterior cervical plate in 2-level cervical anterior interbody fusion patients: Clinical outcomes and radiologic changes. J Spinal Disord Tech, 2012

14. Oh SH YK, Kim YJ, Lee SK: Acdf using the solis cage with iliac bone graft in single level: Clnical and radiological outcomes in average 36 months follow-up. Korean J Spine 10(2):72-77, 2013

15. Schmieder K, Wolzik-Grossmann M, Pechlivanis I, Engelhardt M, Scholz M, Harders A: Subsidence of the wing titanium cage after anterior cervical interbody fusion: 2-year follow-up study. J Neurosurg Spine 4(6):447-453, 2006

16. Smith GW, Robinson RA: The treatment of certain cervical-spine disorders by anterior removal of the intervertebral disc and interbody fusion. J Bone Joint Surg Am 40-A(3):607-624, 1958

17. Williams BJ, Smith JS, Fu KM, Hamilton DK, Polly DW, Jr., Ames CP, et al: Does bone morphogenetic protein increase the incidence of perioperative complications in spinal fusion? A comparison of 55,862 cases of spinal fusion with and without bone morphogenetic protein. Spine (Phila Pa 1976) 36(20): 1685-1691, 2011

18. Wu WJ, Jiang LS, Liang Y, Dai LY: Cage subsidence does not, but cervical lordosis improvement does affect the long-term results of anterior cervical fusion with stand-alone cage for degenerative cervical disc disease: A retrospective study. Eur Spine J 21(7):1374-1382, 2012

19. Yamagata T, Takami T, Uda T, Ikeda H, Nagata T, Sakamoto $\mathrm{S}$, et al: Outcomes of contemporary use of rectangular titanium stand-alone cages in anterior cervical discectomy and fusion: Cage subsidence and cervical alignment. J Clin Neurosci 19(12): 1673-1678, 2012

20. Yang JJ, Yu CH, Chang BS, Yeom JS, Lee JH, Lee CK: Subsidence and nonunion after anterior cervical interbody fusion using a stand-alone polyetheretherketone (peek) cage. Clin Orthop Surg 3(1):16-23, 2011

21. Zdeblick TA, Ducker TB: The use of freeze-dried allograft bone for anterior cervical fusions. Spine (Phila Pa 1976) 16(7):726729, 1991 